their key physician leaders who guided implementation of the intervention at their offices: Bennett Kaye, MD, Children's Healthcare Associates, Chicago, III; Lori Walsh, MD, Glenbrook Pediatrics, Glenbrook, Ill; Judith Neafsey, MD, South Lawndale Neighborhood Health Center, Chicago Department of Public Health, Chicago, Ill; and Jennifer Kim, MD, KomedHolman Health Center, Near North Health Corporation, Inc, Chicago, III.

\section{References}

1. American Academy of Pediatrics Committee on Nutrition. Prevention of pediatric overweight and obesity. Pediatrics. 2003;112:424-430.

2. Cohen D, McDaniel RR Jr, Crabtree BJ, et al. A practice change model for quality improvement in primary care practice. J Healthc Manage. 2004;49:155-170.

3. LeBailly S, Ariza A, Bayldon B, Binns HJ, for the Pediatric Practice Research Group. The origin and evolution of a regional pediatric practice-based research network: practical and methodological lessons from the Pediatric Practice Research Group. Curr Probl Pediatr Adolesc Health Care. 2003;33:124-134.
4. Elder JP, Ayala GX, Harris S. Theories and intervention approaches to health-behavior change in primary care. Am J Prev Med. 1999;17:275-284.

5. Kristal AR, Glanz K, Curry SJ, Patterson RE. How can stages of change be best used in dietary interventions? J Am Diet Assoc. 1999;99:679-684.

6. Maddux JE, Roberts MC, Sledden EA, Wright L. Development issues in child health psychology. Am Psychol. 1986;41:25-34.

7. Golan M, Weizman A. Familial approach to the treatment of childhood obesity: conceptual model. J Nurs Educ. 2001;33:102-107.

8. Center on Media and Child Health, Children's Hospital Boston. The effects of electronic media on children ages zero to six: a history of research. The Henry J. Kaiser Family Foundation Issue Brief, January 2005. Available at: http://www.kff.org/entmedia/loader.cfm?url =/ commonspot/security/getfile.cfmEPagelD $=50552$. Accessed February 18, 2005.

9. American Academy of Pediatrics, Committee on Public Education. Children, adolescents, and television. Pediatrics. 2001;107:423-426.

\title{
The Action Plan Project: Discussing Behavior Change in the Primary Care Visit
}

\author{
Kate MacGregor, $\mathrm{MPH}_{i}$ Sharon Wong, MPH, Claire Sharifi, BS, Margaret Handley, PbD, Thomas Bodenheimer, MD \\ Department of Family and Community Medicine, University of California at San Francisco, San Francisco, Calif \\ Ann Fam Med 2005;3(Suppl 2):S39-S40. DOI: 10.1370/afm.353. \\ Conflicts of interest: none reported
}

CORRESPONDING AUTHOR

Thomas Bodenheimer, MD, Department of Family and Community Medicine, University of California at San Francisco, Bldg 80-83, SF General Hospital, 1001 Potrero Avenue, San Francisco CA 94110,Tbodenheimer@medsch.ucsf.edu

\section{PURPOSE}

$\mathrm{O}$ ften, clinicians fail to discuss health-related behaviors during ambulatory visits. ${ }^{1}$ An action plan is a structured tool that may assist clinicians in initiating such discussions.

An action plan is an agreement between a patient and a caregiver that the patient will attempt a concrete, specific behavior change, for example, a patient may choose to walk twice around the block after lunch on Mondays, Wednesdays, and Saturdays. Action plans are designed to accomplish a small behavior change with a high likelihood of success rather than a large change that is difficult to achieve. According to several studies, when patients can achieve a small success, their selfefficacy (self-confidence in the capacity to make positive lifestyle changes) increases; self-efficacy has been correlated with improved health-related behaviors and clinical outcomes. ${ }^{2-5}$

The objective of the Action Plan Project was to determine the following: (1) whether primary care clinicians would use a new method-the "action plan discussion" - to encourage patients to set goals for health behavior change, (2) whether this new method could be successfully accomplished in the 15 -minute primary care visit, (3) whether clinicians found the method to represent an improvement over previous behavior change discussions with their patients, and (4) whether patients would adhere to their behavior change goals.

This preliminary paper summarizes the methods used to investigate these questions and some lessons learned. Detailed results are forthcoming.

\section{METHODS}

Forty-three primary care clinicians at 8 primary care sites ( 4 safety-net clinics and 4 private practices) in the San Francisco Bay Area participated in the project. Clinicians received a 45 - to 60 -minute training session to describe the intervention and intervention tool-the 
action plan form (available at: http://www.action-plans. org). The training consisted of a brief review of selfefficacy theory, the demonstration by the research team of a mock action plan discussion, and action plan role plays by the clinicians being trained. ${ }^{6}$ Details of the training are available from the corresponding author.

Adults with risk factors for coronary heart disease were invited to meet with a research assistant before a visit with their clinician. Patients who agreed to participate completed a previsit questionnaire asking about their readiness to make a change in healthrelated behavior and their level of confidence that they could make a behavior change. The Action Plan form was then placed on the front of the patient's chart to remind the clinician to engage the patient in an action plan discussion. The research assistant contacted the patients 2 to 3 weeks and 6 months after the action plan discussion to determine whether patients recalled their action plan and the extent to which they were able to achieve their behavior change goals. Clinicians filled out a brief questionnaire immediately after each action plan discussion and at the end of the project.

\section{LESSONS LEARNED}

The results of clinician questionnaires completed at the end of the project indicated that the majority of clinicians found the action plan concept helpful as a guide to discussing behavior change with their patients. The major barrier to initiating action plan discussions with patients was lack of time in the multiagenda primary care visit.

Most patients, when called by telephone 2 to 3 weeks after the action plan discussion with their clinician, remembered their action plan and reported attempting to initiate behavior change based on the action plan. Most patients appreciated the follow-up telephone call. Six-month follow-up data are not yet available.

The major encouraging lesson of the project is the overall positive reaction of both clinicians and patients to the action plan idea. The major discouraging lesson is that action plan discussions are not feasible for clinicians to undertake as a regular feature of the busy primary care visit.

This project also provides a lesson concerning the relationship between research and practice improvement. The 8 practices participating in this study were approached to participate in a research study of limited duration. The practices were not asked to engage in a permanent practice improvement project to increase the quantity and quality of discussions about healthy behavior change with patients. All the time and effort going into the project were placed on the shoulders of research assistants (who disappear once the research is completed) and clinicians (who are unlikely to continue to hold action plan discussions because of lack of time).

Were we to do this project again, we would try to engage the practices in a sustainable improvement project rather than a temporary research study. We would attempt to train nonclinician practice personnel in conducting action plan discussions with patients, and to help the practices find a way to continue these discussions as a permanent feature of their clinical work.

\section{CONCLUSIONS}

The take-home lesson from this project can be formulated as follows: behavior change discussion with patients using action plans is a desirable addition to the primary care enterprise, but primary care clinicians cannot be expected to add these discussions to an already overfilled plate of responsibilities. Other caregivers thus need to be trained and given time to engage in action plan discussions with patients - in consultation with the patients' clinician-and to initiate follow-up contact with patients regarding their action plans. It is essential to engage practices in this improvement process at the very beginning of the project.

To read or post commentaries in response to this article, see it online at http://www.annfammed.org/cgi/content/full/3/Suppl_2/S39.

Key words: Health behaviors; risk reduction behavior; health education; action plans; goal-setting; coronary heart disease

Submitted December 12, 2004; submitted, revised, February 3, 2005; accepted February 13, 2005.

Funding support: This project was supported by Prescription for Health, a national program of The Robert Wood Johnson Foundation with support from the Agency for Healthcare Research and Quality.

\section{References}

1. Ma J, Urizar GG Jr, Alehegn T, Stafford RS. Diet and physical activity counseling during ambulatory care visits in the United States. Prev Med. 2004;39:815-822.

2. Lorig KR, Ritter P, Stewart AL, et al. Chronic disease self-management program: 2-year health status and health care utilization outcomes. Med Care. 2001;39:1217-1223.

3. Anderson RM, Funnell MM, Butler PM, Arnold MS, Fitzgerald JT, Feste CC. Patient empowerment: results of a randomized controlled trial. Diabetes Care. 1995; 18:943-949.

4. McAuley E. Self-efficacy and the maintenance of exercise participation in older adults. J Behav Med. 1993;16:103-113.

5. Lorig K, Holman H, Sobel DS, Laurent D, Gonzales V, Minor M. Living a Healthy Life With Chronic Conditions: Self-Management of Heart Disease, Arthritis, Diabetes, Asthma, Bronchitis, Emphysema and Others. 2nd ed. Boulder, Colo: Bull Publishing Company; 2000.

6. Rollnick S, Mason P, Butler C. Health Behavior Change: A Guide for Practitioners. Edinburgh, Scotland: Churchill Livingstone; 2000. 